and $18.6(6.5) \%, \mathrm{p}=0.028$ and $\mathrm{p}=0.035 ;$ NRDI 480.4 $(256.0) / \mathrm{min}, 314.7(125.6) / \mathrm{min}$ and $379.5(138.0) / \mathrm{min}, \mathrm{p}=0.22$ and $\mathrm{p}=0.012$; Figure 1$)$.

There were no significant differences in cardiac function between baseline and 3M-FU (TAPSE: 2.6 (0.6) mm vs. $2.4(0.4)$ $\mathrm{mm}, \mathrm{p}=1.00$ ) or systolic pulmonary artery pressures (sPAP 36.7 (15.2) $\mathrm{mmHg}$ vs 35.8 (16.2) $\mathrm{mmHg}$, p: 0.50). The TAPSE score in compliant patients seemed to improve $(\mathrm{n}=3 ; 2.3(0.6) \mathrm{mm}$ vs. $2.7(0.3) \mathrm{mm})$ while non compliant patients experienced a deterioration ( $\mathrm{n}=3 ; 2.7(0.5) \mathrm{mm}$ vs. $2.2(0.4) \mathrm{mm}$ ).

Conclusions NIV improves NRD and respiratory parameters in patients with OHS. However, cardiac function does not improve over a three-month period despite the significant improvements in ventilation. These results are influenced by treatment adherence.

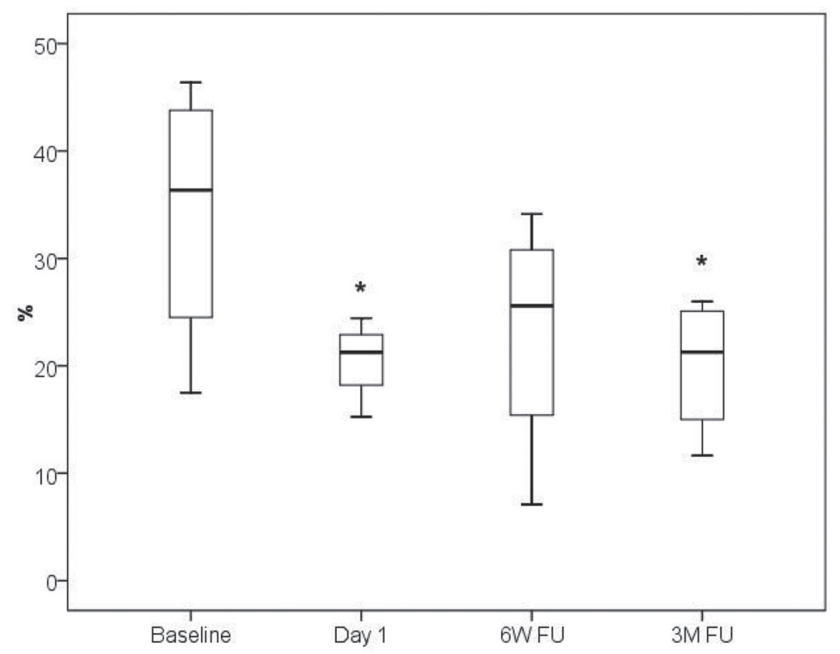

Abstract S56 Figure 1 EMG para\%max improves following setup of NIV And at 3 month in OHS: $\left({ }^{*}\right): p<0.05$

\section{S57 QUALITATIVE ASSESSMENT OF THE EXPERIENCE OF TELEMONITORING IN VENTILATED PATIENTS WITH MOTOR NEURONE DISEASE}

${ }^{1} \mathrm{H}$ Ashcroft, ${ }^{1} \mathrm{H}$ Ando, ${ }^{2} \mathrm{R}$ Halhead, ${ }^{1} \mathrm{~B}$ Chakrabarti, ${ }^{3} \mathrm{CA}$ Young, ${ }^{4} \mathrm{R}$ Cousins, ${ }^{1} \mathrm{RM}$ Angus. ${ }^{1}$ Aintree University Hospital NHS Foundation Trust, Liverpool, UK; ${ }^{2}$ Docobo Ltd, Leatherhead, UK; ${ }^{3}$ The Walton Centre NHS Foundation Trust, Liverpool, UK; ${ }^{4}$ Liverpool Hope University, Liverpool, UK

\subsection{6/thoraxjnl-2016-209333.63}

Background The National Institute for Health and care Excellence (NICE) has recently issued recommendations on the care of people with motor neurone disease (MND), promoting tailored care for each patient, Guideline 42, 2016. Previous studies suggest remote monitoring offers a facility to regularly monitor and interact with patients, providing timely interventions so it may facilitate delivery of the recommendations. The efficacy of this approach is dependent upon acceptability of telemonitoring to patients.

Aim To understand the experiences of using telemonitoring in ventilated patients with MND.

Methods Semi-structured interviews were conducted with seven patients (male $=5$; mean age $=63 \mathrm{yrs}$ ). The median illness duration was $14 \mathrm{~m}$ (range $=7 \mathrm{~m}-13$ yrs $7 \mathrm{~m}$ ) and the median non- invasive ventilation (NIV) usage was $12 \mathrm{~m}$ (range $=0 \mathrm{~m}-3 \mathrm{yrs}$ ). Participants used a telemonitoring device (Docobo CAREPOR$\mathrm{TAL}^{\circledR}$ ) for six months, completed weekly nocturnal pulse oximetry and symptom-related questions. Five caregivers were present at the interviews and provided their feedback. Interviews were audio recorded and transcribed verbatim. Thematic analysis was conducted to find overarching themes. The interpretation was reviewed and supported by a multidisciplinary team examination. Findings Five themes were identified: Technical Challenges, Increased Self-Awareness, Taking Initiative, Benefits of Timely Intervention, and Reducing the Unnecessary. Whilst participants expressed general ease of Careportal ${ }^{\circledR}$ use, technical issues included; messaging system challenges, oximetry transmission, device fault, mobile signal loss. No other negative experience of using Careportal ${ }^{\circledR}$ was reported. Overall, participants expressed how telemonitoring enabled symptom awareness and interpretation. The device also enabled the participants to raise their concerns and/or requests to the healthcare professionals via the messaging system, and this was depicted as a sharp contrast to current communication with hospitals. Timely interventions were observed as a result of regular monitoring, contributing to both physical and psychological well-being of the participants. It was also suggested that using Careportal ${ }^{\circledR}$ could reduce unnecessary cost/time and hassles created by attending hospital appointments. Conclusions Telemonitoring enabled participants to be actively involved in their care and they felt that the interventions were timely delivered to meet their needs. The findings suggest potential benefits of utilising Careportal ${ }^{\circledR}$ in routine care as a contact point to accommodate different individual's needs.

Supported by an SBRI Grant

\section{S58 THE USE OF REMOTE MONITORING TO ASSESS VENTILATOR ADHERENCE AND OUTCOMES WITHIN A REGIONAL HOME MECHANICAL VENTILATION SERVICE}

${ }^{1}$ YM Gn, ${ }^{2} \mathrm{R}$ Moses, ${ }^{2} \mathrm{~A}$ Vyas. ${ }^{1}$ Manchester Medical School, Manchester, UK; ${ }^{2}$ Lancashire Teaching Hospitals NHS Foundation Trust, Preston, UK

\subsection{6/thoraxjnl-2016-209333.64}

Introduction Home mechanical ventilation (HMV) is a recognised evidence-based intervention for patients in chronic respiratory failure (CRF). However there is a paucity of evidence on the adherence to this treatment. This study examined the adherence of HMV and evaluated the clinical outcomes associated with adherence in a variety of patient populations - namely neuromuscular disease, chest wall disease, obesity hypoventilation syndrome and chronic obstructive pulmonary disease (COPD).

Methods A retrospective study was carried out between May to June 2016. Adherence data was downloaded through remote monitoring. Primary outcomes included changes in blood gases at 3 and 6 months, and hospital admissions 12 months pre- and post-ventilation. Qualitative outcomes were obtained through a questionnaire conducted via telephone interviews.

Results 62 patients were included in this study. Patients undertaking remote monitoring of HMV demonstrated an adherence rate of $90.3 \%$, defined as more than 4 hours of ventilator use/night (mean $[\mathrm{SD}]=7 \mathrm{~h} 17 \mathrm{~min}[2 \mathrm{~h} 53 \mathrm{~min}])$. No significant difference in adherence was found between patients of different aetiologies. The blood gases improved significantly at 3 months compared to baseline $(\mathrm{p}<0.05)$. However, there was a universal trend for these parameters to return to baseline at 6 months regardless of the underlying disease. HMV reduced hospital admissions by 